\title{
REPENSANDO A GEOGRAFIA POLÍTICA. UM BREVE HISTÓRICO CRÍTICO E A REVISÃO DE UMA POLÊMICA ATUAL
}

\author{
José William Vesentini ${ }^{1}$
}

\begin{abstract}
Resumo: Este ensaio possui três partes. A primeira analisa a origem da geografia política moderna com Ratzel, procurando mostrar porque esse autor alemão pode ser considerado como o sistematizador desta modalidade de geografia. Também há uma crítica dos limites da geografia política ratzeliana. $\mathrm{Na}$ segunda parte há um breve histórico da geografia política, que é dividida em três fases ou etapas. E na terceira parte do texto retoma-se o debate entre a abordagem nomotética e a ideográfica na geografia política, concluindo-se que ambas coexistem e são importantes para uma análise da política na sua dimensão espacial.
\end{abstract}

Palavras-chave: Política e espaço; Etapas da Geografia política; Nomotético; Idiográfico.

\section{Revendo os Primórdios}

Aexpressão geografia política existe há séculos. Contudo, existe praticamente um consenso, entre os estudiosos da geografia política, que essa modalidade da ciência geográfica teria sido forjada ou iniciada por Friedrich Ratzel com a sua obra Politsche Geographie, editada em 1897 (Cf., entre outros, SANGUIN, 1977a; 1977b; DIKSHIT, 1985; SÁNCHEZ, 1992; COSTA, 1992; RAFFESTIN, 1993; e GLASSNER, 1995).

Sem dúvida que existem alguns poucos que buscam outras origens, mais antigas ou talvez mais "nobres". Afinal, Ratzel ficou estereotipado pela pecha de "determinista", criada pelos franceses no início do século XX2. Mas não é somente por esse motivo que alguns tentam escavar outras origens para essa modalidade da geografia humana. Existem razões de peso, embora discutíveis. Yves Lacoste, por exemplo, além da própria revista por ele editada, Hérodote - cujo primeiro número, no qual esse ponto de vista foi afirmado, surgiu em 1976 - , acredita que a geografia como um todo, em especial a sua vertente "fundamental" ou prática, isto é, a geopolítica - que para ele nada tem de distinto da geografia política - teria sido iniciada já na antiguidade clássica, em especial com Heródoto, no século $\mathrm{V}$ a.C (LACOSTE, 1976). Por sua vez, os geógrafos anglo-saxônicos KASPERSON e VINGHI (1969) iniciam a sua antologia de textos de geografia política com um escrito de Aristótoles, que viveu no século
IV a.C. E um geógrafo francês, numa obra clássica nesta modalidade do saber, argumenta que a geografia política teria sido inaugurada com a obra $O$ espírito das Leis, de Montesquieu, editada no século XVIII (GOTTMANN, 1952).

Entretanto, mesmo esses poucos autores que enfatizam uma origem mais remota para a geografia política, admitem que com Ratzel teria se iniciado uma "nova fase" ou, pelo menos, uma nova abordagem geográfica da política. Ademais, esses referidos autores não fazem qualquer questão de esboçar alguma diferenciação entre a geografia política e a filosofia política (desde que esta, mesmo que remotamente, faça alguma referência ao espaço ou ao território), entre a geografia política e a ciência política (idem), ou até mesmo - no caso de Lacoste e de vários outros - entre a geografia política e a geopolítica.

Mas não existe, praticamente em nenhum estudioso da história da geografia política - a única exceção, parcial, é Claude Raffestin -, uma demonstração mais rigorosa da novidade representada por Ratzel com a sua obra de 1897. Esse clássico autoproclamou ser o iniciador de uma nova modalidade de estudo geográfico (RATZEL, 1988: 1-4) e tal pretensão nunca foi seriamente checada, esmiuçada, arrazoada; foi tão somente reproduzida, inclusive pelos críticos do seu pretenso "método determinista" (Cf. BRUNHES e VALLAUX, $1928)^{3}$.

${ }_{1}$ Professor Livre Docente do Departamento de Geografia da FFLCH da Universidade de São Paulo. (EMAIL)

2 Para um maior aprofundamento a respeito da construção do mito da existência de uma "escola geográfica determinista", teoricamente capitaneada por Ratzel, veja-se o nosso ensaio Controvérsias Geográficas. Epistemologia e Política. In: Revista eletrônica Confins: http://confins.revues.org/

${ }^{3}$ Nesta importante obra clássica de Brunhes e Vallaux - em nossa opinião, o melhor trabalho de geografia política desde o final do século XIX até 1945 -, originalmente editado em 1917 na França, existem inúmeros reproches a Ratzel e, paradoxalmente, uma fiel reprodução do conteúdo - dos temas, da seqüência de assuntos - denominado geografia política pelo investigador alemão. É uma nova proposta de geografia política - ou melhor, "geografia da guerra e da paz" - que dialoga constantemente com os temas e conceitos ratzelianos. 
Qual teria sido, afinal, a novidade representada pela obra de Ratzel? Foi ele quem iniciou, no estudo do fenômeno político, uma preocupação espacial ou geográfica? Ou, ainda, teria sido ele quem criou a expressão "geografia política"?

Não. Nem uma coisa nem outra. Ratzel não foi um pioneiro na incorporação da dimensão espacial no estudo da política e tampouco foi o criador da expressão "geografia política". A bem da verdade, a preocupação teórica com a espacialidade da política ou do político ${ }^{4}$ remonta aos textos clássicos da antiguidade. É praticamente impossível discorrer sobre política - ou sobre qualquer outra atividade humana em sua concretitude - sem um mínimo de preocupação locacional. Mas não é necessário, e nem adequado, apelar para os escritos de Heródoto - onde de fato poderemos encontrar o mais antigo texto, pelo menos do Ocidente, a respeito da política: o diálogo entre Otanes, Dario e Megabises a respeito da melhor forma de governo ${ }^{5}$-, nos quais não existe a menor preocupação em separar fato de fiç̧ão, já que 0 autor, de forma proposital e explícita, inventa personagens e atribui aos deuses determinados desfechos ou ações. Na verdade, foi um autor posterior a Heródoto, Tucídides [como se sabe Tucídides viveu entre 460 e 400 a.C, enquanto Heródoto viveu de 480 a 425 a.C.], quem inaugurou esta tradição de objetividade, que provavelmente é ocidental, de buscar causas e de separar os fatos da ficção ou da interpretação ${ }^{6}$. E foi o estagirita do século IV a.C quem primeiro tematizou, nesses moldes de objetividade - e usando uma lógica da qual foi o grande sistematizador e que se tornaria num dos alicerces da moderna ciência que nasceu nos séculos XVII e XVIII -, a política como objeto autônomo de investigações (ARISTÓTOLES, 1985). Sua obra Política já discorria a respeito do tamanho ideal do território da Pólis, a sociedade política da sua época (Idem: 229-231).

Cabe ainda lembrar que, no século XVII, Maquiavel teceu alguns comentários sobre as relações entre o governo, o Príncipe, e o seu território (MAQUIAVEL, 1979). Mas foi principalmente Montesquieu, no século XVIII, quem mais valorizou a categoria espaço geográfico na vida política. Sua obra principal, 0 espírito das Leis, pode mesmo ser vista como uma tentativa de explicação da política pelas condições geográficas, aí incluídas não apenas os aspectos fisiográficos - especialmente posição, relevo, solos e clima
-, como também o que hoje denominaríamos geografia cultural: os valores e em especial as religiões de cada povo (MONTESQUIEU, 1979). Também Hegel, por sinal um atento leitor de Montesquieu, valorizou o espaço geográfico na sua filosofia da história universal, procurando entendê-lo como "base" ou pré-condição do processo histórico. Nas suas palavras:

\begin{abstract}
"Partimos do pressuposto que a história universal representa a idéia do espírito tal como ele se revela na realidade como uma série de formas exteriores (...) Por esse grau [de consciência de si próprio] estar situado no tempo e no espaço, adquire as características de existência natural (...) Não devemos entender o solo [espaço] como um local externo e sim como o tipo natural da localidade, que corresponde exatamente ao tipo e caráter de um povo, filho desse solo."(HEGEL, 1980:162) ${ }^{7}$
\end{abstract}

Entretanto, apesar disso tudo, acreditamos ser possível argumentar com fundamento que foi efetivamente com Ratzel, na última década do século $X I X$, que se iniciou um estudo geográfico da política, ou, em outras palavras, um estudo sistemático a respeito da dimensão espacial da vida política. Ratzel operou uma (nova) sistematização ou reorganização de um certo saber, inaugurando uma abordagem sobre a política no interior da (então) recém estruturada ciência geográfica. 0 que hoje entendemos como geografia política, destarte, lembra muito não o modelo de Aristóteles, tampouco o de Montesquieu, mas sim a ordenação criada por Ratzel. Explicitando melhor: Ratzel foi o iniciador da geografia política no sentido que esta passou a ter desde o final do século XIX até 0 presente, isto é, como um conjunto de temas interligados: Estado e território, as origens do Estado e as suas relações com o seu espaço físico, a política geográfica ou territorial, a cidade-capital e as suas funções, as relações entre a política e os meios de transportes e de comunicações, o exercício do poder no e com o espaço, os atores políticos e as suas territorialidades, etc. Vamos esmiuçar um pouco mais essa idéia nas linhas a seguir.

\footnotetext{
${ }^{4}$ Uma análise mais apurada - e aguda - dessa diferenciação entre "a" política (como modalidade do saber) e "o" político (como fenômeno), pode ser encontrada em LEFORT, 1991: 251-5.

${ }^{5}$ Cf. HERÓDOTO. 1985: 80-2. Esse famoso diálogo entre Otanes, Dario e Megabises, considerado como o texto pioneiro sobre política, foi bastante trabalhado e valorizado por BOBBIO, 1980: 31-35.

${ }^{6}$ Cf. TUCÍDIDES, 1987. Sobre a novidade historiográfica representada por Tucídides, ver o ensaio de CHAUÍ, 2000.

${ }^{7}$ Podemos encontrar na obra de Ratzel inúmeras passagens que reproduzem, mesmo que não citando, essas idéias hegelianas. De fato, Ratzel foi um leitor atento de Hegel, Montesquieu e Spencer.
} 
Devemos reiterar que na verdade Ratzel não criou o rótulo "geografia política". Esse rótulo, conforme assinala CAPEL (1989), existe há séculos, havendo inúmeras obras dos séculos XVII e $\mathrm{XVIII} \mathrm{com} \mathrm{esse} \mathrm{título.} \mathrm{Na} \mathrm{verdade,} \mathrm{essa} \mathrm{expressão} \mathrm{era} \mathrm{comumente}$ empregada nos estudos sobre tal ou qual país ou continente: seus rios e montanhas, suas cidades principais, a capital, etc. E, por outro lado, Ratzel também não foi o pioneiro na abordagem da dimensão espacial ou territorial da política, que, como já mencionamos, pode ser encontrada, mesmo en passant, nas obras de inúmeros pensadores: Aristóteles, Platão, Cícero, Maquiavel, Montesquieu, Hegel, etc. Todavia, esse geógrafo alemão iniciou uma nova abordagem e, malgrado a superficialidade de algumas de suas análises e observações (pelo menos para nós, hoje; e a bem da verdade também em contraponto com alguns outros autores do século XIX), não há nenhuma dúvida que ele foi o fundador da geografia política moderna. Iremos demonstrar isso a seguir.

Ratzel pode ser legitimamente considerado como o iniciador da geografia política, pelo menos tal como ela passou a ser entendida desde o ocaso do século XIX, por três motivos principais. Em primeiro lugar, Ratzel foi o organizador ou sistematizador de um conjunto de temas e conceitos que, a partir dele, passaram a ser o conteúdo inquestionável de qualquer obra de geografia política, inclusive daquelas elaboradas pelos seus críticos. Na verdade ele construiu um novo campo de estudos, definindo seus "objetos", ou, em outras palavras, seus temas e conceitos fundamentais: as relações da política com o espaço geográfico, nas quais despontam o estudo do território (seu tamanho e formato, sua expansão ou retração, sua localização absoluta e relativa), das fronteiras com a sua tipologia, das cidades-capitais (sua localização no território nacional, sua importância), da política geográfica ou territorial, da circulação pelo território, da importância do "solo" [território] na constituição e na evolução dos Estados, do significado de "grandes potências" ou Estados mundialmente poderosos, da colonização e da guerra enquanto conquista ou domínio territorial.

Qual é, afinal, a estrutura conceitual dessa mencionada obra seminal de Ratzel? O livro foi dividido em seis seções, cada uma delas contendo alguns capítulos, cujo total é dezenove. A primeira seção aborda as relações entre o Estado e o solo [território], argumentando que não existe um poder político abstrato, independente do seu espaço geográfico, e chegando até o conceito de soberania, indissociavelmente ligado a - ou se exercendo em um território delimitado por fronteiras. Um importante conceito que o autor desenvolve é o de política territorial: "Podemos encontrar em todos os momentos da história a diferença essencial entre uma política territorial ou geográfica e uma outra por assim dizer geral ou estritamente política" (RATZEL, 1988: 40).

A segunda seção da obra trata do movimento histórico e o crescimento dos Estados, tematizando as grandes migrações e a mobilidade espacial dos povos, os movimentos históricos e as transformações do Estado, a guerra, os valores político-geográficos, a conquista e a colonização. Cabe assinalar que por vezes se menciona o grande teórico germânico da guerra Karl Von Clausewitz. No entanto, Ratzel entendia a guerra não tanto como um confronto entre diferentes sociedades, tal como Clausewitz, e sim como uma disputa territorial: "[Ela] representa, do ponto de vista geográfico, um movimento potente, brusco e violento, no qual importantes massas humanas de um país penetram num outro país(...) 0 primeiro objetivo da guerra é sempre o de penetrar no território do inimigo." (RATZEL, 1988: 90-1).

A terceira seção enfoca o crescimento espacial dos Estados, tratando da influência das representações geográficas, do papel das idéias religiosas e nacionalistas sobre o desenvolvimento estatal, das etnias e culturas. A quarta seção procura detalhar o que significa posição geográfica do Estado. A quinta seção enfatiza a extensão geográfica dos Estados, relacionando isso com o formato do território, com o "comércio" ou as relações exteriores, com o povoamento e com o poderio dos Estados. Um conceito que surge aqui é o de potência mundial:

"Dependeu do espaço dado em cada época a realidade de quantos Estados deveriam crescer e tornarem-se 'potências mundiais', ou seja, ter o mundo conhecido sob as suas rédeas a fim de lhe comunicar a sua influência. Ter interesses em todo o mundo não implica numa posição de potência mundial; através do comércio mundial, alguns restringidos Estados, como a Bélgica ou a Suíça, possuem esse alcance. Somente o Império Britânico, atualmente, é uma potência grande e ao mesmo tempo extensa que está diretamente presente em todos os países e em todos os mares. Mesmo uma imensa massa territorial como a da Rússia não poderá fazer uma grande potência que seria uma extensão suplementar até 0 Pacífico e uma posição equivalente no Atlântico, pois somente os oceanos abririam uma rota que permitiria à Rússia estender o seu poder até os países do hemisfério ocidental e aqueles do hemisfério sul. Aí está porque a Rússia somente alcançará uma posição mundial no momento em que abrir uma rota até o oceano Índico e assim atingir o Atlântico e o Pacífico." (RATZEL, 1988: 278-9). 
E na sexta e última seção do livro, Ratzel analisa o importante tema das fronteiras: o que são, quais os seus tipos e qual é a sua importância para o Estado e para o seu desenvolvimento. Existe aí a reprodução da idéia, extremamente polêmica e ao que parece de origem francesa, da existência de fronteiras naturais e artificiais ${ }^{8}$.

Não cabe aqui e agora uma crítica às insuficiências da abordagem ratzeliana, que inegavelmente tem um viés etnocêntrico - ou melhor, eurocêntrico - e desvaloriza as culturas não européias ${ }^{9}$, além de superestimar a importância do território no desenvolvimento do Estado (noção que confunde com o desenvolvimento da sociedade, por sinal de forma coerente com o hegelianismo então em moda na Alemanha) e de não enxergar qualquer outra forma de conflito e luta que não o externo, a guerra entre Estados.

Isso tudo já foi realizado, total ou parcialmente, por uma série de autores, que mostraram como Ratzel teve uma percepção limitada de soberania, como foi ingênuo ou demasiado naturalista ao advogar a existência de "fronteiras naturais", como teve um entendimento limitado da política (centrada somente no Estado e ainda por cima o encarando como um organismo darwiniano que "luta pela sobrevivência"), etc. Longe de ter sido um pensador complexo, como querem alguns atualmente, Ratzel com freqüência elaborava raciocínios simplistas quando abordava temas de geografia política. $\mathrm{Na}$ verdade, ele foi mais um sistematizador [de idéias ou conceitos elaborados anteriormente por outros], com poucas idéias realmente originais, do que um pensador crítico. Acreditamos não haver dúvidas que ele foi um excelente sistematizador de temas geográficopolíticos, sendo nesse sentido o criador ou o sistematizador da moderna geografia política. Ademais, ele entendeu muito bem, melhor que seus colegas geógrafos contemporâneos, o que seria a política na sua dimensão espacial ou geográfica. Cabe ainda realçar, mais uma vez, que mesmo os críticos de Ratzel acabaram por dar prosseguimento, de uma forma ou outra, ao seu projeto de uma nova abordagem geográfica da política. Sem a menor dúvida, a partir de Ratzel a geografia política deixou de ser um rótulo utilizado para o estudo, normalmente descritivo, deste ou daquele país ou continente, para se tornar no estudo da política na sua dimensão espacial.

Em segundo lugar, Ratzel foi provavelmente o primeiro geógrafo que compreendeu - ou que escreveu sobre isso - o que realmente significa política no sentido moderno da palavra. Apesar de - ou talvez devido a - uma inequívoca influência do naturalismo darwiniano em toda a sua obra, não há nenhuma dúvida que a sua concepção de política é maquiavélica, é devedora do realismo de Maquiavel. Ou seja, é um entendimento moderno de política. Acredito que seja possivel afirmar que Ratzel foi, direta ou indiretamente (via Spencer e principalmente via Darwin e o darwinismo vulgarizado, no qual a evolução biológica é vista somente como competição e luta ${ }^{10}$ ), um leitor de Maquiavel.

Maquiavel, como se sabe, operou uma reviravolta no entendimento do fenômeno político. 0 mestre florentino superou a visão, então dominante, da atividade política como "natural" ou como uma decorrência da manifestação divina, insistindo numa forma de atividade coletiva, exercida plenamente pelos homens - que são dotados de livre arbítrio e agem segundo determinadas circunstâncias datadas, mas que podem ser modificadas pela ação humana ${ }^{11}$-, isto é, pelos grupos sociais, pelos indivíduos, pelo Estado em particular.

De acordo com a interpretação de três especialistas, "Quaisquer que sejam as continuidades (ou filiações) entre a Antiguidade e a Idade Média, por um lado, e os Tempos Modernos, por outro, o 'secretário florentino' introduziu uma ruptura decisiva; contra as teorias da sociabilidade natural, contra os ensinamentos da Revelação e os da teologia, ele afirma - porque constata - que, no que se refere às atividades coletivas, o que é o Estado. Foi ele quem deu a este último termo sua significação de poder central soberano legiferante e capaz de decidir, sem compartilhar esse poder com ninguém, sobre as questões tanto exteriores quanto internas de uma coletividade." (CHÂTELET, PISIER-KOUCHNER e DUHAMEL, 1985: 38).

Em Maquiavel - como também em Ratzel, embora sem a mesma agudez ou profundidade de análise - a política se exerce noe

\footnotetext{
${ }^{8}$ BRUNHES e VALLAUX (1928: 308-14) argumentam que a idéia de fronteiras naturais é "antiquada", afirmando, com total razão, que são os grupos humanos - na sua expansão, nas suas disputas - quem determinam o traçado das fronteiras, inclusive quando estas se identificam com rios ou montanhas. Nesse sentido toda fronteira seria "artificial", ou melhor, cultural. MACHADO e STEIMAN (2002), com base no geógrafo britânico Norman Pounds, assinalam que a idéia de "fronteira natural" teria surgido no século XVI na França.

${ }^{9}$ Veja-se, por exemplo, este trecho do livro: "Todos os grandes Estados do passado e do presente foram obras de povos civilizados. Esta lição é evidenciada pelo fato de que praticamente todos os grandes Estados dos dias de hoje estão situados na Europa ou em zonas coloniais européias. A China é o único grande Estado, de dimensão continental, a evidenciar uma outra esfera cultural diferente da européia." (RATZEL, 1988: 192).

${ }^{10}$ Abrindo um parêntese, é interessante recordar a posição do geógrafo e anarquista Prior KROPOTKIN (1970), que em pleno final do século XIX polemizava com esse darwinismo em voga, demonstrando que a "evolução" em todos os seus aspectos - biológico, econômico e social - pressupõe não apenas a competição e a luta, com a (duvidosa) "sobrevivência dos mais fortes", como também é marcada pela cooperação ou ajuda mútua entre indivíduos, grupos, gêneros, etnias e espécies.
} 
pelo Estado, sendo este visto como um representante da coletividade e aquela atividade como "A política é uma forma de guerra e, sem dúvida, não é por acaso que, para nos fazer compreendê-lo, Maquiavel tenha escolhido raciocinar inicialmente sobre o caso da tomada do poder pelas armas; mas, devemos também reconhecer, que essa guerra obedece a imperativos particulares e não depende da violência pura (...) 0 autor dá a fórmula dessa política quando nota que os homens 'devem acariciar-se ou trucidar-se', mas, devemos entender que os dois termos dessa alternativa são igualmente aplicáveis conforme o caso: na realidade é preciso acariciar uns e trucidar outros e isto pela mesma razão que sustenta a lógica das relações de força(...) Estratégia que vemos claramente não ser inspirada por qualquer outra consideração afora a preocupação de conservação e crescimento da potência." (LEFORT, 1980:34-5).

Em inúmeras ocasiões Ratzel demonstra que entendeu essa lição, ou seja, que a política é antes de tudo uma relação de forças. De forma até exagerada, sem enfatizar o livre arbítrio dos homens e vendo na sociedade, na população, não o escopo (e muito menos o sujeito) da atividade política, mas sim, essencialmente, uma força a serviço do Estado:

"Os pais da estatística e os homens de Estado de sua época viam na população o critério de potência do Estado(...) Essa superestimação política da demografia surgiu a partir de Colbert, na era do despotismo esclarecido. 0 fato de termos percebido que o fator espaço tem uma importância maior não nos deve levar a uma subestimação do fator população, mas ao contrário, ver nela um denominador com o qual se pode avaliar corretamente o valor político da extensão [territorial]. A concepção da população como uma força do Estado não coincide totalmente com 0 seu valor. Nas regiões onde 0 comércio de escravos sobrevive, a população tem um valor mercantil (...) No curso do desenvolvimento da humanidade se desenha uma alta do valor da população e portanto um aumento do valor político do efetivo demográfico. Isso por duas razões. $O$ crescimento espacial engendra um aumento populacional, o que nos leva a constatar como o valor do espaço condiciona aquele dos homens; está aí uma das fontes desse crescimento de valor. A segunda está ligada ao aumento do valor do trabalho dos indivíduos. A força das antigas culturas residia ainda numa valorização massiva das forças de trabalho individuais para a construção de templos ou pirâmides(...) [e] um Estado com uma população numerosa e vigilante dispõe também de uma potente força militar." (RATZEL, 1988:306-7).

E finalmente, em terceiro lugar, como já observou com perspicácia um geógrafo suíço (RAFFESTIN, 1993), Ratzel iniciou uma abordagem - ou um projeto - nomotética da geografia política, que anteriormente era estudada de maneira exclusivamente idiográfica. Isso significa que ele procurou conceituar território, fronteiras, cidades-capitais, política geográfica ou territorial, as relações entre 0 Estado e o espaço, etc, diferentemente dos seus antecessores, que estudavam as fronteiras da França (ou dos Estados Unidos), o território da Rússia (ou da Inglaterra), a cidade-capital da Suíça (ou da Espanha) e assim por diante. Ele se preocupou com os conceitos em si, independentemente dos casos particulares, que só entram na sua obra enquanto exemplificações das suas teorias gerais. Ele tentou enfim construir uma ciência da geografia política, entendendo como ciência - de forma coerente com a sua época, fortemente marcada pelo darwinismo e pelo positivismo (Cf. CAPEL, 1981: 267-305; e MORAES, 1990: 7-27) - tão somente um saber nomotético, que busca as "leis" ou os princípios gerais, os conceitos em si, aplicáveis a qualquer situação.

Já na apresentação da primeira edição de sua obra, editada "no verão de 1897", Ratzel esclarece que buscou complementar, na análise científica da política, aquilo que falta à sociologia e à ciência política:

"Aos olhos de certos politicólogos e sociólogos, como também para numerosos historiadores, o Estado paira no ar, e o território estatal nada mais é do que uma forma superior de propriedade fundiária. A geografia política, ao contrário, não pode fundamentar o seu approach do Estado a não ser em relação com o seu solo terrestre. Para ela, o Estado não é outra coisa que uma realização humana, realidade que não pode se completar sem um solo [território] sobre a superfície terrestre(...) Tal é a concepção que norteia esta obra, na qual os Estados serão analisados, em todos os estágios

\footnotetext{
11 "Não me é desconhecido que muitos têm a opinião de que as coisas do mundo são governadas pela fortuna e por Deus, de sorte que a prudência dos homens não pode corrigi-las (...) Não obstante, e porque o nosso livre arbítrio não desapareça, penso ser verdade que a fortuna seja árbitra de metade de nossas ações, mas que ela nos deixe governar a outra metade (...) Julgo feliz aquele que combina o seu modo de proceder com as particularidades dos tempos." (MAQUIAVEL, 1979: 104-5).
} 
de seu desenvolvimento, como organismos que mantêm relações necessárias com o solo e, dessa forma, podem ser consideradas sob um ponto de vista geográfico (...) Eles [os Estados] se apresentam como formas definidas e localizadas no espaço, como parte de uma série de fenômenos que a geografia tem como objeto descrever, mesurar, reproduzir e comparar segundo os procedimentos científicos." (RATZEL, 1988: 2-3)

Convém notar que Ratzel procurou se inspirar nos exemplos da sociologia e da ciência política, modalidades do conhecimento científico mais identificadas com a abordagem nomotética. Em vários trechos desse livro, ele denota um menosprezo pela história - embora, de forma hegeliana, faça algumas referências à História como um processo teleológico linear, mas sempre depreciando a história como eventos ou processos particulares -, um saber cuja natureza idiográfica é flagrante. Para realçarmos o significado dessa atitude, temos que lembrar que tradicionalmente - em Kant, principalmente, que serviu de alicerce epistemológico para toda uma geração de geógrafos que inclui Humboldt e Ritter - a geografia sempre foi muito mais identificada com a história.

Um pouco mais adiante, no primeiro capítulo do livro, Ratzel esclarece que:

"Podemos definir a política como o espírito de um Estado ou sua individualidade espiritual (...) A idéia política não contém, portanto, somente o povo, mas também o seu território. Dessa forma, sobre um solo dado, o Estado só pode se desenvolver como uma única potência política, suscetível de extrair desse solo o seu valor político (...) O Estado não pode, sem se enfraquecer, tolerar a presença de um outro e de um terceiro sobre esse solo (...) Friedrich List foi o primeiro entre os economistas a distinguir claramente o significado econômico e político do território nacional de um povo. Na época em que ele elaborou o seu sistema, a economia política estava sob a influência teórica de Adam Smith, na qual não se via mais do que 'um sistema de economia privada englobando todos os indivíduos de um país'; a esse sistema, List opôs a sua própria teoria relativa aos meios pelos quais uma nação pode assegurar ou melhorar a sua posição política em função da situação mundial do momento e das circunstâncias próprias a esta nação." (RATZEL, 1988: 17-8. Os grifos são nossos).

Mas a necessidade de fundar uma análise científica, nos moldes da sua época marcadamente positivista e darwinista, leva
Ratzel a naturalizar a política e conseqüentemente o Estado, vendoo numa perspectiva lógica - não histórica, mas organicista - como um coroamento da evolução biológica e civilizacional de um povo:

"Os elementos últimos de um organismo estatal são os grupos sociais; os indivíduos não possuem, a não ser excepcionalmente, uma significação imediata para o Estado(...) Na maior parte dos casos, são as famílias e os clãs de parentesco, as comunidades locais, as organizações militares, as companhias comerciais ou as associações religiosas que conquistam a terra, que trabalham e se ocupam sob a autoridade e em função do Estado. 0 mais importante de todos esses grupos é a família, comunidade natural do homem, da mulher e das crianças (...) $\mathrm{O}$ organismo difere de um agregado pela divisão do trabalho, na qual existem os órgãos. 0 organismo estatal forma órgãos mediante as disparidades que apresentam 0 solo e a distribuição espacial da população sobre ele. Daí porque encontraremos sempre num primeiro plano as grandes oposições entre zona periférica e zona central, litoral e interior, planície e montanhas, cidade e campo, regiões populosas e regiões desabitadas de um Estado. Inúmeras diferenças históricas, inclusive dentro dos Estados, repousam sobre esses fundamentos geográficos."(Idem: 24-5).

Cabe assinalar que Ratzel, num sucinto item do capítulo 1 , observa que a comparação do Estado com um organismo "não é totalmente fecunda". Todavia, ele não aprofunda essa distinção e continua nesse mesmo capítulo detalhando essa sua visão organicista do Estado. Isso reflete tanto a sua formação original, como naturalista (biólogo), como também a forte influência do darwinismo vigente na sua época. Mas é bom deixar claro que autores contemporâneos ou mesmo anteriores a Ratzel - como Maquiavel, por exemplo, ou mesmo Marx, ou os anarquistas, além de outros - já haviam superado essa leitura organicista da sociedade e do Estado

\section{Os desdobramentos}

O que ocorreu com a geografia política a partir de Ratzel? Como podemos periodizá-la? Esse "projeto nomotético" de Ratzel, tal como o denominou Raffestin, continua a nortear os rumos da geografia política atual?

Comecemos pela periodização. Desde essa obra seminal de Ratzel até a atualidade, a geografia política, de uma maneira geral levando em conta as "grandes produções" internacionais e deixando de lado as especificidades ou particularidades em tal ou qual "escola nacional" neste ou naquele contexto particular -, atravessou pelo 
menos três fases ou momentos relativamente distintos: do final do século XIX até a Segunda Guerra Mundial, de 1945 até os anos 1970 e desta última década até o presente ${ }^{12}$.

De forma esquemática e simplificada, podemos afirmar que cada uma dessas fases correspondeu, direta ou indiretamente, a uma conjuntura internacional específica: a ordem mundial multipolar conflituosa do final do século XIX até a Segunda Guerra Mundial, a ordem bipolar de 1945 em diante e a crise da bipolaridade (e principalmente da sua ideologia) a partir dos anos 1970. Por sinal é exatamente a conjuntura internacional da época de Ratzel o fator que mais contribuiu para o sucesso e a expansão desta proposta ratzeliana de um novo estudo geográfico da política. Não podemos esquecer que até mesmo a geopolítica foi criada, pelo menos oficialmente, após uma leitura de Kjellén desta obra de Ratzel. E inúmeros cientistas sociais, além de estrategistas estatais, passaram a prestar mais atenção à dimensão geográfica da política ou, em outras palavras, à importância da geografia (física e humana) para a política internacional e em especial - naquele momento de bipolaridade conflituosa, na qual havia um declínio da grande potência hegemônica, o Reino Unido, e a ascensão de outras grandes potências mundiais que de uma forma ou de outra propugnavam por uma "nova ordem mundial" - para as disputas mundiais por poder.

A primeira fase da geografia política - ou pelo menos desta "nova" geografia política inaugurada por Ratzel -, do final do século XIX até 1945 , foi marcada por uma forte base nacional, ou seja, o que existia de fato eram "escolas nacionais" de geografia - notadamente a alemã, a francesa e a britânica - que competiam de forma acirrada, inclusive colocando os seus "interesses nacionais" - ou corporativistas no sentido de uma corrente (nacional) específica acima dos cânones científicos ou, às vezes, até mesmo éticos pelo nosso entendimento atual. (Digo isso porque não era incomum que as idéias de um autor "alienígena" fossem reproduzidas sem a correspondente citação, inclusive com acirradas críticas às suas pretensas teorias, que eram desvirtuadas. Isso foi muito freqüente na geografia francesa em relação a Ratzel, por exemplo). Houve uma quase total identificação da geografia política com a geopolítica, em especial na "escola alemã" - e também na anglo-saxônica em geral -, principalmente porque ambas tinham as mesmas bases epistemológicas (positivismo ou historicismo, e/ou naturalismo e darwinismo), eram exacerbadamente nacionalistas e abordavam alguns grandes temas comuns: a noção de grande potência mundial, relações entre espaço ou território e poderio estatal, as fronteiras como zonas problemáticas e conflituosas, o colonialismo e a ordem (geo)política internacional, a "necessidade" de estabelecer as bases teóricas para que um determinado Estado-nação se fortalecesse na Europa ou no mundo, etc.

Os próprios nomes e obras representativos desta fase ilustram bem essas características: os escritos de Vidal de La Blache sobre Ratzel ou sobre as regiões da Alsácia e Lorena; as importantíssimas obras de Sir Halford MacKinder, um dos principais forjadores da "escola geográfica britânica" e tido como o maior teórico da geopolítica clássica; os textos de Nicholas Spykman nos Estados Unidos; e as obras de Jean Brunhes e de Camille Vallaux, além de Jacques Ancel, na França, etc ${ }^{13 .}$

A segunda fase, de 1945 até o início dos anos 1970, foi marcada por vários traços. Primeiro, um rompimento com a geopolítica, que passou a ser vista como uma pseudo-ciência. Segundo, e de forma complementar, por um maior rigor teóricometodológico, com uma ênfase na cientificidade - agora não mais identificada com o naturalismo de inspiração darwiniana e sim com o neopositivismo de inspiração einsteiniana e/ou popperiana ${ }^{14}$, com o funcionalismo ou às vezes com o materialismo histórico - no lugar da busca do poderio para tal ou qual Estado-nação. Terceiro, com preocupações com a guerra fria, com ideologias e com os sistemas sócio-econômicos (o capitalismo e o socialismo). Ocorreu ainda um enfraquecimento das escolas francesa, britânica e, principalmente, da alemã, com um correlato fortalecimento da escola nacional norte-americana, que se tornou a mais importante (em geografia política) no pós-guerra. Isso se deveu aos seguintes motivos. A Europa se encontrou durante algum tempo arrasada pela guerra e tentando se reerguer, algo que diminuiu consideravelmente as verbas para pesquisas, além de levar a uma emigração de inúmeros pensadores e cientistas desse continente para os Estados Unidos - no caso de geógrafos que de alguma forma contribuíram para a geografia política, podemos mencionar os casos de Jean Gottmann, Leo Waibel, David Harvey e vários outros -, que os convidava para trabalhar em condições bem mais vantajosas que na Europa, tanto

\footnotetext{
${ }^{12}$ Reproduzimos aqui, pelo menos em parte (até os anos 1970), a periodização sugerida por SANGUIN, 1977: 5-35. A caracterização da nova fase, a partir dos anos 1970, é de nossa exclusiva responsabilidade.

${ }^{13}$ Não vamos arrolar aqui os títulos dessas obras, além de outras também representativas, algo enfadonho e muito descritivo, apesar de importante para aqueles que se aprofundam no tema. Uma relação completa, com todas as referências, de dezenas de obras desta e da próxima fase da geografia política podem ser encontradas no mencionado texto de SANGUIN (1977b).
} 
sob o ponto de vista de proventos como de condições operacionais (apoio em recursos humanos, bibliotecas, laboratórios, etc.). Cabe recordar que muitos intelectuais já tinham ido da Alemanha para os Estados Unidos antes mesmo da eclosão da guerra devido ao regime nazista que perseguia pensadores judeus, pensadores de esquerda, liberais, etc. E também o maior poderio econômico e político-militar dos Estados Unidos no pós-guerra, quando esse país assumiu de fato a condição de superpotência, fez com que fossem necessários estudos, pesquisas e reflexões sobre a ordem mundial, sobre a correlação internacional de forças nesta ou naquela região do globo, enfim sobre as relações entre a política e o espaço geográfico.

Os autores e escritos mais significativos desta segunda fase foram os de Richard Hartshorne (sobre a abordagem funcionalista na geografia política), de N. Pounds [que, segundo SANGUIN (1977b), escreveu o "primeiro manual de abordagem sistemática" sobre esse assunto], os de Saul Cohen (sobre geografia e política num mundo dividido), os de Jean Gottmann (sobre a política dos Estados e a sua geografia, e também sobre o significado de território), os de L.M.Alexander (sobre modelos políticos mundiais) e vários outros ${ }^{15}$.

E, finalmente, a terceira e atual fase da geografia política se inicia na segunda metade da década de 1970 e se encontra em aberto, num momento de indeterminações e com uma crescente e rica produção. Podemos afirmar que houve uma espécie de "renascimento" - ou melhor, uma grande expansão com abordagem crítica de velhos temas e a invenção de novos - da geografia política a partir dos anos 1970. A influência de determinados acontecimentos políticos marcantes a partir do final dos anos 1960. As lutas contra a guerra do Vietnã e pelos direitos civis nos Estados Unidos. 0 maio de 1968 na França e em outros países. 0 advento de novos sujeitos - como os movimentos sociais, o movimento feminista [que, inclusive, deu origem à geografia feminista], as lutas dos afro-americanos por direitos, as demandas dos homossexuais, etc. -, além de novas formas de luta ou de contestação. A crise do planejamento centralizado e do marxismo e, posteriormente, a derrocada do socialismo real. E o advento da globalização e da chamada nova ordem mundial. Todos esses fatos ou processos foram decisivos para o desenrolar desta nova fase da geografia política.
Afinal, a geografia política é o estudo da política na sua dimensão espacial, e todos esses acontecimentos de uma forma ou de outra contribuíram para mudar a vida política e ao mesmo tempo o nosso entendimento sobre ela.

Não podemos ainda negligenciar as influências de fora, da filosofia ou das ciências sociais em geral. A geografia política, pelo menos desde Ratzel, sempre dialogou com importantes pensadores de outras áreas do conhecimento: Aristóteles, Maquiavel, List, Montesquieu, Spencer, Hegel, Weber e outros. Nesta nova fase, inúmeros filósofos ou cientistas sociais se tornaram importantes para as redefinições desta modalidade da geografia: Michel Foucault com a sua nova concepção de poder (ou melhor, poderes, que são indissociáveis do uso ou da reorganização dos espaços); Henri Lefebvre e a sua idéia de produção do espaço (social); Claude Lefort e o enigma do político, além da "invenção democrática"; Cornelius Castoriadis com a sua crítica ao marxismo juntamente com a idéia (neoanarquista, com forte influência de Kropotkin) de autonomia; a escola de Frankfurt com a sua "teoria crítica", lida principalmente a partir das contribuições de Habermas; além das contribuições de Antony Giddens, de Manuel Castells, dos geógrafos anarquistas Elisée Reclus e Prior Kropotkin (que foram e são relidos sob novas perspectivas).

Também a geopolítica deixou de ser exorcizada e foi reincorporada na análise geográfico-política, seja de forma crítica (para alguns) ou de forma entusiástica e com freqüência acrítica (para outros). 0 Estado deixou de ser 0 ator político privilegiado (e praticamente exclusivo) e agora existe uma ênfase no(s) poder(es), que não se identifica somente com o Estado - embora, evidentemente, também com ele -, mas com vários outros fenômenos ou sujeitos: por exemplo, a sexualidade, o uso do corpo, a (re)organização do espaço, o advento de novos atores com as suas diferentes territorialidades, enfim com novas formas de luta e tensões, com novos poderes - ou micro-poderes - e o uso que fazem do espaço. Das lutas tão somente no/pelo espaço [visto como natureza, ou natureza reelaborada pela ação humana], passou-se também à analise das lutas com o espaço [visto como construção do social].

${ }^{14}$ Gostaríamos de deixar claro, para evitar algum possível mal-entendido, que não estamos rotulando Albert Einstein e nem mesmo Karl Popper de neopositivistas, algo que seria absurdo principalmente em relação ao brilhante cientista alemão. (Em relação ao filósofo austríaco a questão é mais complicada, com ele se dizendo um crítico do positivismo - que equivocadamente identifica com o empirismo -, enquanto que outros - Adorno, Habermas, etc. - asseveram que a sua epistemologia é positivista). Pensamos que essas escolas de pensamento, o positivismo clássico e o neopositivismo, só têm sentido para as ciências humanas. Nenhum físico importante nos séculos XIX ou XX - tais como Maxwell, Einstein, Bohr, Planck, Heisenberg e outros -, jamais levou a sério e tampouco "aplicou" nas suas pesquisas a filosofia positivista. Esta última, na realidade, é em grande parte uma tentativa de ver na física um "modelo" para todas as demais ciências, desprezando as profundas diferenças que existem entre o mundo físico e a sociedade humana. ${ }^{15}$ Vide a nota de rodapé $n .13$. 


\section{Uma polêmica revisitada}

Nosso objetivo aqui, com esta lacônica síntese histórica da geografia política, não foi o de analisar minuciosamente os seus desdobramentos a partir do final do século XIX. Foi, isso sim, uma forma de evidenciar - com vistas a polemizar - uma questão a nosso ver essencial: a continuidade do projeto nomotético ratzeliano. Pois acreditamos, neste ponto concordando com RAFFESTIN (1993), que praticamente toda a geografia política posterior a Ratzel compartilhou com ele - mesmo que eventualmente 0 criticando, procurando suprir algumas lacunas da sua obra, acrescentando novos sujeitos ou territorialidades, introduzindo uma nova maneira de enxergar 0 fenômeno político, etc. - essa aspiração em construir uma "ciência nomotética" da abordagem geográfica da política. Nas suas palavras:

"Todo o projeto ratzeliano é sustentado por uma concepção nomotética, e pouco importa, nesta fase da análise, saber se ela foi ou não bem sucedida (...) Pode-se considerar que a sua obra não somente orientou e influenciou a escola alemã, mas também, de diferentes maneiras, todas as outras escolas de geografia (...) A obra ratzeliana, lançando as bases da geografia política, traçou um quadro no qual ainda se pode trabalhar mesmo quando a ela nos opomos, como foi o caso da escola francesa (...) Pode-se mesmo dizer que nos contentamos em explorar a 'mina ratzeliana'. O que pode parecer novo é aquilo que Ratzel, voluntária ou involuntariamente, deixou na sombra." (RAFFESTIN, 1992: 12-5).

Nesses termos, podemos então colocar uma questão a nosso ver fundamental: Como ficou ou como fica então a abordagem idiográfica na geografia, especialmente na geografia política? Ela sem dúvida caiu no ostracismo, mas será que realmente tornou-se superado com o sucesso dessa proposta nomotética de Ratzel?

Sabemos que Kant valorizava bastante essa forma de abordagem, que a seu ver seria imprescindível à história, principalmente, e também à geografia. Nesta, provavelmente foi Hartshorne, não por coincidência um neokantiano que pesquisou primordialmente temas de geografia política, o último geógrafo a apregoar, mesmo que de forma meio acanhada e titubeante, a validade de uma abordagem idiográfica. Recordando algumas de suas palavras sobre 0 assunto:

"O fato de a geografia constituir um dos campos do conhecimento em que uma soma relativamente grande de esforços é empregada no estudo de casos individuais, e não na tentativa de elaborar leis científicas, tem preocupado os críticos, em nosso meio, há mais de meio século (...) Não há dúvida que todos nós podemos concordar com Hettner, que a ciência não há de permitir que o conceito do livre arbítrio a impeça de procurar determinar as causas das ações humanas ao máximo de sua capacidade como ciência (...) [Todavia] afirmar que a ciência refutou a possibilidade de um certo grau de livre arbítrio, ou que se pode esperar que ela venha refutar essa possibilidade, seria pretender saber 0 que não podemos conhecer. [Muitos] aferram-se ao determinismo científico [isto é, o estabelecimento de "leis" nomotéticas para toda a realidade], como um artigo de fé filosófica que deve ser defendido na qualidade de alicerce do qual depende a estrutura da ciência. Qualquer sugestão de dúvida, a menor presunção de que existe a possibilidade do livre arbítrio, deveria, por conseguinte, ser atacada com veemência e escárnio como sendo anticientífica (...) A nossa conclusão é a seguinte: quer pelo fato de que um certo grau de livre arbítrio é uma realidade, quer pela circunstância de que jamais poderemos conhecer de maneira completa os fatores e processos que determinam as decisões humanas individuais, sempre há de permanecer uma área oculta em qualquer estudo no campo das ciência sociais, que não poderá ser explicado por leis cientificas. Em resumo, como afirma Allix, 'o único determinismo verdadeiro é o estatístico'. Mas em muitos aspectos da ciência importa conhecer determinados casos individuais. As mais fidedignas estatísticas de mortalidade não serão capazes de dar uma resposta à secular pergunta de quem indaga: 'quanto tempo de vida eu ainda terei?' (...) Asseverar, como fazem alguns, que a formulação de leis científicas constitui o propósito final da ciência, é confundir os meios com o fim. O propósito da ciência é compreender o universo ou a realidade, com o maior grau de fidedignidade possível. Embora os cientistas do século XIX confiantemente esperassem que todo o conhecimento da realidade seria em breve organizado segundo leis gerais, nenhum domínio logrou reduzir todos os seus resultados a esses termos, e não podemos hoje prever que isso jamais seja possivel (...) A geografia busca descrever e classificar fenômenos, estabelecer, sempre que possível, princípios lógicos ou leis gerais, alcançar o máximo de compreensão sobre as inter-relações entre esses fenômenos e organizar esses resultados em sistemas ordenados. Podemos substituir a indagação 'A geografia é uma ciência?', pela pergunta muito mais útil: 'Que espécie de ciência é a geografia?' A geografia é um campo cuja matéria inclui a maior complexidade de fenômenos, e, ao mesmo tempo, preocupa-se, mais do 
que a maioria das demais ciências, com o estudo de casos individuais - dos inumeráveis lugares do mundo e do próprio caso ímpar do [nosso] mundo. Por essa razão, a geografia é menos capaz do que muitas outras ciências de elaborar e empregar leis científicas. Mas, não obstante isso, a exemplo de outros domínios científicos, ela preocupa-se em elaborar leis na medida do possível." (HARTSHORNE, 1969: 222-9).

Não desconhecemos que este texto de Hartshorne, originalmente publicado em 1959, foi uma resposta a determinadas críticas feitas ao seu monumental trabalho de 1939, The Nature of Geography, nas quais vários geógrafos norte-americanos - a começar por Schaefer - fustigaram em especial a sua caracterização da geografia como um saber idiográfico. Mas não estamos aqui interessados na evolução do pensamento desse autor $e$ tampouco nos principais lances daquele famigerado debate sobre o "excepcionalismo na geografia". Nosso interesse principal aqui e agora não é o debate ocorrido nos Estados Unidos nos anos $1960 \mathrm{e}$ sim a validade ou não da abordagem idiográfica na geografia política. Ipso facto, esta longa citação de Hartshorne nos coloca frente a um importante debate epistemológico na história do pensamento geográfico, que, a nosso ver, necessita ser retomado sob outras bases e com um novo enfoque. Talvez mais na geografia política do que nas demais modalidades da ciência geográfica, em especial na geografia física. Mas não se trata de historiar numa perspectiva descritiva esse debate, muito menos o de ver no célebre texto de Fred SCHAEFER (1953), que com base em Karl Popper afirmou que a abordagem ideografica não é científica, um marco para o advento da modernidade na geografia, como foi realizado de forma simplória ${ }^{16}$.

$\mathrm{Na}$ realidade, não é tanto o caso de se retomar esse debate e sim o de repropor os seus termos, substituindo essa enviesada problemática do "excepcionalismo" na geografia - rótulo que por si só já implica num entendimento (neo)positivista - por uma outra mais atual e profícua, sobre o papel do contingente, do acaso, do não completamente determinável, e até mesmo do livre arbítrio do ser humano (algo reconhecido por Hartshorne, um leitor de Maquiavel e de Kant, mas ignorado ou menosprezado pelos seus críticos) nos processos sociais e históricos.

Apesar da limitada visão que Hartshorne tinha da geografia - como uma ciência corológica, que estuda as diferentes áreas ou regiões da superfície terrestre (perspectiva que também encerra um elemento de verdade, embora não dê conta de toda a produção geográfica passada, presente ou em devir) -, temos que concordar com ele que a função primordial da ciência não é estabelecer "leis" gerais e sim conhecer a realidade. Determinadas "leis" ou princípios lógicos até podem ter - e têm efetivamente - o seu lugar, dependendo da realidade estudada. Mas elas são instrumentos do conhecimento, em contextos nos quais isso é possível, e não 0 seu objetivo primordial. A realidade ou o "mundo" no sentido geral, tudo o que existe e/ou que pode ser conhecido enfim, é complexo e multifacetado e nada nos garante que um método adequado para uma área do conhecimento também o seja para uma outra diferente. Um dos principais dogmas do positivismo, em todas as suas vertentes (inclusive em determinados meios "dialéticos" ou marxistas), é a crença de que existe um único método válido para todos os aspectos da realidade, para todo o conhecimento científico. A ciência atual caminha numa direção oposta a essa, numa aceitação da pluralidade - de métodos e de procedimentos, de formas de conhecimento ou de explicações - do real, conforme atesta um importante filósofo:

"Se o método, no sentido profundo do termo, pudesse ser unificado por toda a parte, a diversidade de regiões [do real, do conhecimento] se reduziria a uma diversidade simplesmente aparente (...) Uma tal unificação mais ou menos direta dos métodos parece fora de questão hoje, talvez para sempre. Não é nem mesmo possível considerá-la dentro do domínio antropológico [isto é, nas ciências humanas]." (CASTORIADIS, 1987: 214$)^{17}$.

Fred Shaefer, no seu famoso artigo, cognominou de "excepcionalismo" esse ponto de vista corológico na geografia, no qual o objetivo desta ciência seria não o de estabelecer leis gerais e sim conhecer casos (regiões, lugares) particulares. Em suas palavras:

"O pai do excepcionalismo é Immanuel Kant. Mesmo sendo considerado como um dos grandes filósofos do século XVIII, Kant foi um geógrafo medíocre quando comparado aos seus contemporâneos ou mesmo a Bernardo Varenius, que morreu mais de um século e meio antes dele. Kant produziu a sua asserção excepcionalista não somente para a geografia, mas também para a história. Segundo ele, a história e a geografia

${ }^{16}$ Cf. GOMES, 2000: 245, onde se afirma que esse artigo de Shaefer marcou o final do "período clássico" da geografia e 0 advento da modernidade entendida como "o seu [da geografia] alinhamento ao método científico" [sic!]. 
encontram-se numa posição excepcional, diferente das chamadas ciências sistemáticas (...) Ritter usou essas idéias, assim como Hettner e finalmente Hartshorne (...) O que os cientistas fazem é (...) aplicar em cada situação concreta todas as leis que envolvem as variáveis que eles consideram como relevantes. As regras pelas quais essas leis são combinadas, o que é livremente chamado interações das variáveis, estão elas mesmas entre as regularidades que a ciência tenta descobrir. Não há nenhum desafio, como imagina Hartshorne, para o cientista social produzir uma lei singular que poderia explicar a complexidade da situação do porto de Nova lorque. Uma descrição dessa situação é única no óbvio senso que nunca haverá uma região ou localidade exatamente como Nova lorque com todos os serviços que fornece para o seu entorno. Nunca haverá uma lei para um caso assim. Pois, que importância teria uma lei que levasse em conta somente um caso? Mas, por outro lado, a geografia urbana atualmente conhece alguns princípios sistemáticos os quais, aplicados ao porto de Nova lorque, podem explica, não tudo mas alguma coisa, sobre a estrutura e as funções dessa realidade. Esse é o ponto. Ou devemos desistir de explicar porque nós não podemos explicar todas as coisas? Nesse ponto a geografia encontra-se na mesma situação das outras ciências sociais. Ou devemos rejeitar a sociologia porque a predição sobre o resultado das eleições não é ainda tão confiável como alguns gostariam, ou porque não podemos assegurar com certeza se em cinco anos a Argentina terá uma ditadura ou uma democracia? (...) Qualquer um que rejeite o método científico em qualquer área da natureza, rejeita por princípio a possibilidade de predição. Em outras palavras, rejeita o que é normalmente conhecido como determinismo científico. A atitude intelectual por trás dessa atitude na maioria dos casos é alguma versão da doutrina metafísica do livre arbítrio [sic!]. (...) Se determinismo é entendido como a existência generalizada de leis na natureza, sem nenhuma 'exceção', então essa é a base comum de toda a ciência moderna (...) O que podemos inferir disso tudo sobre o futuro da geografia? Parece-me que desde que os geógrafos cultivem os aspectos sistemáticos da sua disciplina, a geografia é uma ciência como outra qualquer. Todas as formas de leis que distinguimos contêm fatores espaciais (...) [Mas] eu não sou otimista no caso da geografia rejeitar a busca de leis, exaltando os aspectos regionais e graças a isso limitar-se a uma mera descrição. Neste caso, os geógrafos sistemáticos deverão se encaminhar para e finalmente se integrar nas ciências sistemáticas." (SHAEFER, 1953: 246-9. Os grifos são nossos).

Tentemos destrinçar as filigranas desse raciocínio de alguém que pretendeu legislar sobre uma ciência sem nunca ter realizado qualquer pesquisa significativa. Em primeiro lugar, é patente a reprodução do discurso neopositivismo então em moda, de inspiração popperniana ${ }^{18}$, que naquele moment ${ }^{19}$, encarava a física como o modelo por excelência a ser seguido por qualquer disciplina que se pretendesse científica. Não existiriam diversidades no real, tampouco nas ciências, mas apenas um paradigma único de busca de leis ou princípios lógico-matemáticos, de preferência construídos de forma dedutivista (a indução e a ênfase no empírico em si eram menosprezados), que comporiam o âmago do conhecimento científico. É óbvio que a ciência nunca conheceria tudo ou a "essência" das coisas - tal como na imagem kantiana (assumida por Popper e desconhecida por Schaefer) do navegante que se orienta pela estrela Polar sem nunca a alcançar -, mas acumularia gradativamente um rol de conhecimentos (ou melhor, de leis e/ ou teorias) que permitiriam uma previsão cada vez mais apurada dos fatos, advindo daí uma forte recusa em analisar os casos particulares ou únicos, que só teriam algum sentido se incorporados num esquema ou numa teoria classificatórios. As teorias ou "leis" nomotéticas, afinal, deveriam necessariamente desembocar numa forma de previsão e qualquer conhecimento que não atendesse a esse requisito seria não-científico. ${ }^{20}$

Mas e se alguma região ou aspecto do real não atender a essa exigência, se em determinado campo do conhecimento não for possível construir leis dedutivistas ou tentar prever que tal fato poderá ou não ocorrer? A resposta para isso, segundo as próprias palavras do "mestre" Popper, é que esse seria um domínio mitológico ou pseudo-científico e nunca um conhecimento verdadeiramente científico: foi exatamente esse o seu "julgamento" da psicanálise e de todo o estudo do inconsciente humano, por exemplo (cf. POPPER, 1967: 44-6).

Em segundo lugar, há uma desvirtuação dos "oponentes", começando por Kant e terminando pelo alvo preferencial a ser atingido, Hartshorne. Ignora-se, provavelmente de forma deliberada, que esses autores jamais advogaram um "excepcionalismo" puro e simples (isto é, um caráter único, completamente diferente de todo o restante, como se esse restante - isto é, a ciência - fosse homogêneo) para a geografia ou a história, mas sim uma ênfase na complexidade e na diversidade do real e, portanto, das ciências. Basta lembrar daquele importantíssimo trecho de Hartshorne, no

\footnotetext{
${ }^{17}$ Também um conhecido especialista em filosofia da ciência argumenta que existem ciências, no plural, e não apenas uma ciência: GRANGER, 1994.
} 
qual ele afirma que mais útil do que inquirir "se a geografia é uma ciência" seria refletir sobre "que tipo de ciência é a geografia", numa evidente percepção de que a realidade não é a mesma em todas as suas manifestações e, dessa forma, existiriam ciências (no plural) e não "a" ciência.

O que na realidade Kant asseverou, por sinal de forma bastante razoável, foi que existem diversas formas de conhecimento, do artístico ao filosófico, do científico (que pode ser mais ou menos nomotético ou idiográfico e nunca exclusivamente uma coisa ou outra) ao senso comum, etc, e eles não são estanques ou sequer hierarquizados. E nem Kant e tampouco Hartshorne afiançaram que a geografia seria um saber totalmente idiográfico; eles apenas admitiram que a realidade estudada pela geografia e principalmente pela história tem muito de particular ou de irrepetível (isto é, não recorrente) e, dessa forma, cabe utilizar, embora não de maneira exclusiva, uma abordagem idiográfica.

Em terceiro lugar, existe nesse texto uma ojeriza da monografia, de qualquer estudo aprofundado sobre uma realidade específica nas suas determinações (e indeterminações) particulares: isso é visto como uma mera "descrição" (e não uma explicação), numa total desvalorização não apenas da geografia regional, mas também da biologia, embora de forma inconsciente na medida em que Popper nunca estudou seriamente outras ciências naturais além da física e em particular as teorias de Einstein. De maneira até mesmo hilária, no final do texto de Shaefer ameaça abandonar à sua própria sorte a geografia regional - ou a perspectiva geográfica que "exalta os aspectos regionais" -, caso ela não mude radicalmente, e se juntar de vez ao time dos cientistas sistemáticos (ele pensava em especial na economia, vista pelos neopositivistas como a ciência social mais próxima do seu modelo de ciência). Evidentemente que não há nenhuma análise sobre a história, que sempre enfrentou dilemas mais ou menos semelhantes aos da geografia (só que no tempo ao invés de no espaço), disciplina que perpassa todas as ciências sociais e ao mesmo tempo é relativamente distinta delas apesar de - ou devido a - ser a base privilegiada e indispensável sobre a qual elas se edificaram.

No entanto, a despeito da flagrante debilidade desse ponto de vista, o fato é que esse viés neopositivista obteve uma profunda repercussão na geografia, em especial na anglo-saxônica. A partir daí a abordagem regional na geografia sofreu um enorme declínio, da mesma forma que as tentativas de integrar o natural com o social. A geografia norte-americana, a partir dos anos 1960, procurou imitar 0 exemplo das ciências sociais e em especial o da economia, tornandose numa espécie de prima pobre da "economia espacial". O discurso sobre o espaço como categoria abstrata substituiu as análises sobre os fenômenos na sua dimensão espacial. O próprio David Harvey, por exemplo, provavelmente o nome mais conhecido dessa escola geográfica desde os anos 1970, mesmo tendo nas suas palavras operado um deslocamento de uma abordagem "liberal" até uma "marxista" (HARVEY, 1980: 7), nunca deixou de lado uma percepção de ciência com uma forte influência do artigo de Schaefer. A sua concepção de pesquisa, mesmo depois que optou pelo marxismo, continua sendo a de aplicar "o" método científico, no singular (só que agora usando menos a matemática, como uma linguagem unificadora, e mais o materialismo histórico, com a mesma função), sem nunca aprofundar as determinações concretas de qualquer situação específica - isto é, sem nunca encarar um processo, um lugar ou uma obra (um edifício, por exemplo) em sua singularidade mesmo que contextualizada - e sempre tentando elaborar "leis" ou conceitos gerais que dêem conta de tudo num mesmo esquema. Seu entendimento, expresso numa obra clássica de 1969, com ligeiras alterações, continua a nortear a sua produção em temas como a justiça social ou a condição pós-moderna:

"Os geógrafos tiveram grandes dificuldades para libertar-se dessa forma particular de explicação (o método idiográfico). (...) A tese kantiana [na qual a geografia seria um saber idiográfico] supõe também que o espaço pode ser examinado, e os conceitos espaciais desenvolvidos, independentemente do seu conteúdo. O que é lamentável é que essa afirmação de um espaço absoluto não tenha sido explicitamente discutida e reconhecida como uma das proposições básicas da tese kantiana(...) Podemos concluir que a geografia é escassa em teorias e muito rica em fatos. Podemos afirmar que as leis [científicas] podem ser estabelecidas tanto na geografia física quanto na humana(...) O complicado e multivariado sistema que os geógrafos tentam analisar (sem as vantagens do método experimental) é difícil de manejar. A teoria, em última instância, requer o uso da linguagem matemática, pois somente se pode manejar a complexidade de interações

${ }^{18} \mathrm{O}$ autor submeteu o texto, antes da publicação, à leitura e sugestões do filósofo (e seu amigo) Gultav Bergmann, um discípulo (e ex-aluno) de Karl Popper. ${ }^{19}$ Popper sofisticou o seu ponto de vista mais tarde, após os debates de 1969 com a Escola de Frankfurt. Cf. ADORNO, T., POPPER, K. e outros (1973). 20 "Há um critério para se determinar o caráter ou status científico de uma teoria? (...)Afirmo que o critério para se estabelecer o status científico de uma teoria é a sua refutabilidade ou a sua testabilidade. Uma teoria que não é testável não é científica. Toda 'boa' teoria científica implica numa proibição: proibição de que ocorram certas coisas." (POPPER, 1967: 43-7). 
de forma consistente usando semelhante linguagem. A análise dos dados requer um computador rápido e métodos estatísticos adequados, e a verificação das hipóteses também requer métodos. A incapacidade dos geógrafos em desenvolver teorias reflete em parte um lento crescimento dos métodos matemáticos apropriados para tratar os problemas geográficos. Os deterministas realizaram toscos intentos de explicação sistemática, porém nos anos 1920 caíram em desgraça." (HARVEY, 1969: 64-8) ${ }^{21}$.

Percebe-se nessa fala uma recusa em distinguir a realidade natural da social e uma total desconsideração pela questão do livre arbítrio do ser humano, além do fato - muito estranho para quem apregoa estar considerando não mais o "espaço absoluto" de Newton e de Kant, mas sim o "espaço relativo" de Einstein de ignorar completamente a problemática da indeterminação de certos processos (inclusive físicos, tal como enuncia o "princípio da indeterminação" de Heisenberg ${ }^{22}$, referendado por Einstein).

Mesmo em seus trabalhos mais recentes, por sinal de excelente qualidade, prevalece um esquematismo lógico-formal que denega as contradições inerentes e as indeterminações do(s) objeto(s) estudado(s), nos quais a "justiça social" é subsumida a uma problemática de "produção e distribuição" (ignorando assim as contradições históricas e principalmente as lutas sociais que determinam a sua realidade específica em tal ou qual contexto), e a "dualidade" entre modernidade e condição pós-moderna é vista como reflexos da produção fordista (estandardizada, baseada na economia de escala, etc.) e da produção flexível (economia de escopo, descentralização e diversidade, etc. Cf. HARVEY, 199223). Enfim, a tentativa de superação da abordagem idiográfica, a exorcização do original ou do singular ${ }^{24}$, resultou, em grande medida, numa análise depauperada, que generaliza em demasia e - malgrado a sua prolixidade - perde completamente as especificidades de cada situação ou processo.

Todavia, cabe esclarecer que não estamos advogando os méritos da "abordagem idiográfica" contra os "nomotéticos" e muito menos assumindo aquele discutível e limitado ponto de vista - que veio de Kant, passou por Hettner e talvez tenha se encerrado com Hartshorne - segundo o qual a geografia estuda as "diferenciações de áreas" na superfície terrestre. 0 que objetivamos demonstrar é que a crítica - necessária - da geografia como um saber essencialmente idiográfico, destarte, foi superficial em demasia e perdeu algo importante no seu percurso. Ela não consistiu afinal numa verdadeira crítica - na qual deve existir uma superação com subsunção ou incorporação do que foi criticado como parte de uma síntese superior - e sim numa mera rejeição.

Em função de um modismo - ou comodismo - epistemológico25, denegou-se a contradição inerente ao social-histórico, a indeterminação do fenômeno político enquanto relação de forças, o papel do contingente ou do acaso e a relação problemática entre sujeito e objeto no estudo do social:

${ }^{21}$ Também RAFFESTIN (1993: 23-4) vai por um caminho semelhante, afirmando que o grande problema de Ratzel na sua tentativa de superar a abordagem idiográfica e estabeler "leis" era a fragilidade dos métodos estatísticos da sua época.

22 "Na mecânica quântica as relações de incerteza impõem um limite máximo definido na precisão com que posição e momento linear, ou tempo e energia, podem ser medidos simultaneamente. Como uma separação infinitesimalmemente estreita significa uma imprecisão infinita com respeito às posições no espaço-tempo, os momentos lineares ou as energias ficam completamente indeterminadas." (HEISENBERG, 1995: 123).

${ }^{23}$ Nessa importante obra, talvez o livro (acadêmico) de geografia com maior difusão internacional nos últimos 20 anos, 0 autor consegue discorrer sobre temas variados - a renovação urbana de Baltimore, a problemática da habitação popular em Los Angeles, o prédio da IBM em Nova lorque ou o filme Blade Runner - sem nunca mencionar os seus contextos específicos, as contradições e os grupos ou projetos alternativos que se entrecruzaram, quem saiu vitorioso e porquê, etc., mas apenas catalogando-os como "modernos" ou "pós-modernos". Também não existe nenhum mapa, nenhuma localização no espaço concreto desses fenômenos estudados, mas tão somente considerações abstratas sobre "o significado de espaço e tempo" neste ou naquele filme, na pós-modernidade [sic!], etc.

${ }^{24}$ Não desconhecemos que BUNGE (1982: 521-30) estabeleceu uma esdrúxula diferenciação entre o único ou original e o singular, sendo que este último, a ser levado em consideração pela ciência geográfica, seria tão somente um caso específico e sempre enquadrável numa teoria geral, ao passo que aquele primeiro consistiria num mal-entendido da geografia tradicional, em suma em algo que não existiria na realidade ou que não teria valor para o conhecimento científico. Mas essa perspectiva nos parece facciosa e somente aceitável pelo pressuposto de que existiria um só tipo de conhecimento, o nomotético. ${ }^{25}$ "Como escreveu Norbert Wiener, 'o sucesso da física matemática tornou o homem das ciências sociais ciumento da sua potência, sem que ele compreenda verdadeiramente as atitudes intelectuais que contribuíram para isso. Exatamente como tribos primitivas adotam modas ocidentais de roupa cosmopolita $e$ de parlamentarismo a partir de um vago sentimento de que essas vestimentas ridículas e esses ritos mágicos os levarão diretamente ao nivel da cultura e da técnica modernas, assim também os cientistas sociais forjaram-se o hábito de vestir de modo ridiculo as suas idéias, a bem dizer imprecisas, da linguagem do cálculo infinitesimal'. A razão desse fracasso é clara: são escassos os aspectos dos fenômenos sociais que satisfazem às condições da teoria matemática." (CASTORIADIS, 1987: 215). 
"Impossível falar da História no singular (...) Devemos nos interrogar sobre as formas da história: sobre a distinção entre uma história regida por um princípio de conservação ou de repetição e de uma história que por princípio abre lugar para o novo (...) O que é, pois interrogar? Em um sentido é fazer o enterro do seu saber. Em um outro sentido, aprender graças a esse enterro. Ou ainda: renunciar à idéia de que haveria nas coisas mesmas (...) um sentido inteiramente positivo ou uma determinação em si prometida ao conhecimento, como se isso que analisamos não se tivesse já formado sob o efeito de um deciframento de sentido, em resposta a um questionamento da história, da sociedade (...) como se o 'objeto' não devesse nada a nossa própria interrogação, o movimento do pensamento que nos faz ir até ele e às condições sociais e históricas nos quais se exerce." (LEFORT, 1979: 15-7).

A relação de complementaridade entre objeto e sujeito, a identificação e tensão entre 0 investigador e a realidade a ser estudada (a política na sua dimensão espacial), o fenômeno político como conflito e indeterminação, o livre arbítrio do ser humano, enfim a questão da coexistência entre a necessidade (lógica ou determinação) e a contingência (abertura para o novo, singularidade ou originalidade): eis os elementos basilares a serem incorporados na análise geográfico-política, mesmo sem deixar de lado a superação do idiográfico puro e simples e a necessidade de construir categorias, conceitos ou princípios lógicos, sempre abertos e provisórios e nunca se sobrepondo, de forma dedutiva, a qualquer realidade a ser estudada, que sempre encerra as suas determinações específicas.

Como já assinalaram vários autores (Cf., entre outros, BRUNHES e VALLAUX, 1928), a geografia política é a modalidade da ciência geográfica mais próxima da história, é um dos flancos privilegiados onde elas se imbricam ou se sobrepõem parcialmente. Logo, a problemática do irrepetível, dos processos únicos e originais, da tensão entre necessidade (determinação) e contingência (indeterminação) é algo essencial na reflexão geográfico-política. Isso não significa que ela seja uma forma de conhecimento essencialmente idiográfica, mas sim que esta abordagem também tem um lugar, mesmo sem desconsiderar a elaboração de teorias ou conceitos gerais.

E não se deve confundir, como fizeram Schaefer e vários outros, o idiográfico com o descritivo, pois nem todo estudo de um caso único é descritivo e, em contrapartida, também pode existir a descrição do objeto estudado numa teoria nomotética. Sem dúvida que a geografia política anterior a Ratzel era idiográfica e descritiva, mas não é necessário que esses dois atributos coexistam; ademais, cabe lembrar que a descrição continua a desempenhar um papel importante em determinadas áreas do conhecimento científico, inclusive em algumas ciências naturais hoje consideradas como paradigmáticas ou avançadas (como na genética e em vários outros campos da biologia).

Em síntese, podemos reafirmar que, em geografia política, podemos e devemos levar em conta - e refinar constantemente - os conceitos nomotéticos: por exemplo, aqueles de fronteiras, território e territorialidade, poder ou poderes, Estado (em suas diversas formas históricas e geográficas), cidade-capital, ordem internacional, grande potência mundial, potência regional ou média, etc. Só que não podemos nunca ignorar o estudo específico, que nunca consiste somente na "aplicação" de conceitos ou teorias gerais (apenas os trabalhos medíocres fazem isso), de tal Estado concreto na sua formação territorial específica, desta ou daquela fronteira ou cidade-capital, de tal ou qual ordem geopolítica internacional, etc., com todas as suas determinações (e indeterminações) características. Esperamos que os escritos a seguir, nos próximos capítulos deste trabalho ${ }^{26}$, ajudem a esclarecer esse nosso ponto de vista, no qual a geografia política é simultaneamente um saber nomotético e idiográfico (sem ser descritivo) e onde os estudos de caso contribuem para enriquecer os conceitos que nunca são ou estão completamente acabados.

${ }^{26}$ Este ensaio foi originalmente escrito como parte, como introdução da nossa tese de livre-docência, defendida em 2003. Daí esta referência sobre os próximos capítulos. 
VESENTINI, José William (2010). Rethinking the Political Geography. A brief critical history and the review of a still present controversy. Revista do Departamento de Geografia, n. 20, p. 127 - 142

\begin{abstract}
This essay has three parts. The first one analyses the Ratzel's origin of the Political Geography, what has tried to demonstrate how this German author could be consider as the sistematizer of this kind of Geography. There is also a critical analysis about the limits of the ratzelian Political Geography. In the second part there is a brief history of the Political Geography, which is divided in three stages or phases. The third part summarizes the argument between the nomothetic and the idiographic approach in Political Geography. The conclusion is that both approaches coexist and are important for analyzing the politics in the spatial dimension.
\end{abstract}

Key words: Politics and space; Stages of Political Geography; Nomothetic; Idiographic.

Recebido em 15 de novembro de 2008, aceito em 13 de junho de 2010

\section{Referências}

ADORNO, T., POPPER, K. e Outros. (1973) La disputa del positivismo em la sociologia alemana. Madrid, Grijalbo.

ARISTÓTOLES. (1985) Política, Brasília, Editora da UNB.

BOBBIO, Norberto. (1980) A teoria das formas de governo. Brasília, Editora UNB.

BRUNHES, J. e VALLAUX, C. (1928) Geografia de la historia; geografia de la paz y de la guerra en la tierra y en el mar. Madrid, Daniel Jorro.

BUNGE, W. (1982) Perspectivas de la geografía teorica, in: MENDOZA, J.G., JIMÉNEZ, J.M. e CANTERO, N.O. El pensamiento geográfico. Madrid, Alianza, pp.521-30.

CAPEL, H. (1989) Geografia humana y ciencias sociales: una perspectiva histórica. Barcelona, Montesinos.

CAPEL, H. (1981) Filosofía y ciencia en la geografía contemporánea. Barcelona, Barcanova.

CASTORIADIS, C. (1987) As encruzilhadas do labirinto/1. Rio de Janeiro, Paz e Terra.

CHAUI, M. (2000) O mito fundador do Brasil, in Folha de S.Paulo, 26/03/2000, p.3.

CHÂTELET, F., PISIER-KOUCHNER, E. e DUHAMEL, O. (1985) História das idéias políticas. Rio de Janeiro, Jorge Zahar.

COSTA, W.M.da. (1992) Geografia política e geopolítica. São Paulo, Hucitec/Edusp.

DIKSHIT, R.D. (1985) Political Geography. New Delhi, Tata McGrawHill.

GOMES, P.C.da Costa. (2000) Geografia e Modernidade. Rio de Janeiro, Bertrand Brasil.

GLASSNER, M.I. (1995) Political Geography. New York, John Wiley \& Sons.
GOTTMANN, J. (1952) La politique des États et leur géographie. Paris, Armand Colin.

GRANGER, Giles Gaston. (1994) A ciência e as ciências. São Paulo, Editora da Unesp.

HARTSHORNE, Richard. (1969) Questões sobre a natureza da geografia. Rio de Janeiro, IPGH.

HARVEY. D. (1980) A justiça social e a cidade. São Paulo, Hucitec. HARVEY, D. (1969) Explanation In Geography. Londres, Edward Arnold.

HARVEY, D. (1992) A condição pós-moderna. São Paulo, Loyola.

HEGEL, G.W.F. (1980) Lecciones sobre la filosofía de la historia universal. Madrid, Alianza Universidad.

HEISENBERG, Werner. (1995) Física \& Filosofia. Brasília, Editora da UNB, $3^{\mathrm{a}}$. Edição.

HERÓDOTO. (1985) Histórias. Brasília, Editora da UNB.

KASPERSON, R.E. e MINGHI, J.V. (1969) The structure of political geography. Chicago, Aldine Publising Company.

KROPOTKIN, P. (1970) El apoio mutuo, un factor de evolucion. Buenos Aires, Proyección.

LACOSTE, Y. (1988) La Géographie, ça serve, d'abord, a faire la guerra (1976); A Geografia - isso serve, em primeiro lugar, para fazer a guerra. Campinas, Editora Papirus.

LEFORT, Claude. (1991) Pensando o político. Rio de Janeiro, Paz e Terra.

LEFORT, Claude. (1980) Sobre a lógica da força. In: QUIRINO, C.G. e Souza, M.T.S.R. (Org.). O pensamento político clássico. São Paulo, T.A. Queiroz Editor, pp.34-5.

LEFORT, C. (1979) As formas da História. São Paulo, Brasiliense.

MACHADO, L.O. e STEIMAN, R. (2002) Limites e Fronteiras Internacionais. Uma discussão histórico-geográfica. Rio de 
Janeiro: Grupo Retis/UFRJ, disponível in www.igeo.ufrj.br/ fronteiras/pdf/liafront.pdf.

MAQUIAVEL, N. (1979) O Príncipe. São Paulo, Abril Cultural, coleção Os Pensadores.

MONTESQUIEU, (1979) O espírito das Leis. São Paulo, Abril Cultural, coleção Os Pensadores.

MORAES, A.C.R.(1990) "Introdução". In: Ratzel. São Paulo, Ática. Col.Grandes Cientistas Sociais.

POPPER, Karl. (1967) El desarrollo del conocimiento cientifico. Buenos Aires, Paidos.

RAFFESTIN, C. (1993) Por uma geografia do poder. São Paulo, Ática.
RATZEL, F. (1988) Géographie Politique. Paris, Éditions Régionales Européennes.

SÁNCHEZ, J.E. Geografia Política. (1992) Madrid, Editorial Sintesis.

SANGUIN, André-Louis. (1977a) La Géographie Politique. Paris, PUF.

(1977b) "A evolução e a renovação da geografia política", in Boletim Geográfico, Rio de Janeiro, IBGE, n.252, pp.5-35.

SHAEFER, F.K. (1953) "Exceptionalism in geography: a methodological examination". In Annals of the Association of American Geographers, n.43, pp.226-49.

TUCÍDIDES. (1987) História da guerra do Peloponeso. Brasília, Editora da UNB. 